\title{
A Systematic Review of Tablet Technology in Mathematics Education
}

\author{
https://doi.org/10.3991/ijim.v13i08.10795 \\ Alexander Svela ${ }^{(\varpi)}$, Jalal Nouri \\ Stockholm University, Stockholm, Sweden \\ alexander.svela@gmail.com \\ Olga Viberg \\ Royal Institute of Technology, Stockholm, Sweden \\ Lechen Zhang \\ Stockholm University, Stockholm, Sweden
}

\begin{abstract}
In 2019, the mobile learning body of knowledge is extensive and much is known about the technology impacts and affordances of mobile devices in educational settings. A particular focus has now shifted toward specific technologies in specific subjects. Mathematics is one such subject and tablets are one such technology that is gaining attention. This systematic review representing the latest generation of tablet technology within the tablet-mediated learning in mathematics body of knowledge sought to derive evidence that supported questions into (a) what math sub-disciplines were covered, (b) what technology (application/hardware) was utilized, and (c) what pedagogical approaches were deployed in educational settings. This included analysis of the (d) advantages and (e) disadvantages present in those elements. Thirty-nine relevant articles were collected from various academic technology and educational databases. The results demonstrate that tablets are being predominantly deployed in various sub-disciplines such as Arithmetic, Computation, and Geometry with the iPad as the dominant choice for tablet hardware/applications. Pedagogical approaches lean heavily on game-based learning, environment interaction, and special needs support. Technological advantages include increased collaboration and mathematics engagement enabled by tablet mobility and a high potential for customization of solutions. Developers, teachers, and researchers need to be informed of potential challenges in designing content for tablet technology deployments in mathematics.
\end{abstract}

Keywords-Tablets, evidence, mathematics, systematic review, mobile learning, tablet-mediated learning

\section{$1 \quad$ Introduction}

The impact of technology on mathematical education and the importance of tabletmediated learning is recognized as an important area of study [1]. Mathematical skills 
and competencies are seen as key life competencies and are crucial for "active engagement in all aspects of life" [2 p.1]. Since the launch of the current generation of tablets in 2010, the development of tablet hardware technology has reached a mature state [3]. This allows for more stable platforms for applications to be developed for educational use. The popularity of tablets has led to an increased interest in educational applications, especially in schools [4]. A major driver toward this development of tablet technology is the adoption of said technology within mathematical faculties. Many global governments have introduced procurement programs for schools to enable purchase and supply of tablets to their faculty and student bodies [5] [6] [7]. The development of such programs is a direct result of the combined efforts of the academic community in the last eight years within the field of tablet-mediated learning.

Because use of tablets has the potential to enhance learning, researchers during the last years have become interested in the tablets' affordances in the learning process and their effects on students' achievements [2]. In their review of tablet use in schools, [4] highlighted several affordances of tablets that contribute to improving learning. They include: i) high usability and integration of multiple features (e.g., built-in cameras, accelerometers, and microphones) within one device, ii) easy customization and supporting inclusion, iii) touch screen, as well as iv) availability and v) portability. Furthermore, the authors pinpoint that applications developed for tablets may be "simpler and more "intuitive" to use than their counterparts used with technologies such as laptops [...] because tablet-based application are designed to work with a range of screen sizes and as they often lack the notion of opening and closing applications" (p.10). In comparison with most computers, tablets that incorporate touch interaction make possible manipulation that is similar to how children manipulate physical objects and exploit their natural sensorimotor form of interaction [8] [9].

Moreover, in contrast to computers and mobile phones, tablets' touch screen supports the interaction of two or more students as the same time which makes them especially suited for collaborative work [10]. After all, the small screen size of mobile devices is an obstacle to learning, especially because of the difficulty in collaboration with shared digital displays [11]. Tablets have also been shown to support multimodal learning, i.e., the use of different and combined modalities (e.g., text, sound, video and pictures) to support learning and meaning-making and to support learners to become both producers and consumers of knowledge material [12].

However, certain technologies are considered to be more suitable for chosen tasks than others. In relation to tablets' use, keyboards, larger screens and special software may be needed to support some specific tasks, for instance, mathematical constructions and computer programming [4]. Furthermore, the results of the research on the affective aspect of learning indicate that tablets contribute to students' engagement and sustain their interest (e.g., [13] [14]). Also, [15] found that students preferred learning with tablets compared to text-books. 


\section{Background}

Previous meta-studies and reviews within tablet-mediated and computer-supported learning in mathematics education have focused on: (1) technological impacts on learning effectiveness (high, medium, low) [16]; (2) learning outcomes/gains from usage of tablet technology (positive, neutral, negative) [1] [17]; (3) educational spaces, as classrooms and laboratories [18]; (4) effective educational programs, such as classroom management, motivation, and supplemental tutoring programs [19]; (5) instructional improvement strategies (technology and nontechnology curricula, manipulatives, and technology tools) [20]; and (6) educational cohorts (K-12, higher education) [16] [17]. Each of these studies either focuses purely on the broader application of computer technology in mathematics or where tablets were the focus, mathematics was not due to a broader overall learning approach.

Furthermore, tablet-mediated learning can be seen as a part of the mobile learning research field. Although there is much debate on what comprises and defines mobile learning in its entirety, there is a growing consensus that the subcategory of 'tools' is one such included factor within the technology area (e.g., [21] [22]). Hence, several relevant reviews focusing mobile learning in mathematical education rather than tablet-mediated learning per se have been conducted (e.g., [23] [24] [25]). In these studies, tablets are largely considered as one of many other mobile devices, without any particular focus on their specific affordances and/or characteristics in terms of user interaction patterns. One of the recent reviews of mobile learning for science and mathematics school education [23] emphasized the review of empirical evidence. However, similarly, the authors have not focused and/or examined specific affordances of tablets compared to other mobile technologies used. In the same vein, [24] reviewed mobile learning in mathematics only reported that tablets, in relation to the types of mobile devices used, were next in frequency (31\%) after mobile phones (38\%); no analysis of the differences between tablets and other mobile technologies has been presented.

With the high-level understanding of where tablets are located within the mobile learning body of knowledge, it is important to reflect upon previous research where these tools are concerned. In addition to a host of individual journals on the subject, several previous systematic reviews have examined research where tablets have been employed in education. Firstly, [18] analyzed the iPad's instructional benefits in educational settings. Despite finding 'tempting technology features' and 'ease of use' as drawing factors toward using the iPad as an educational tool, they could not conclude that the iPad had any positive academic effect in respect to tablet-mediated learning outcomes - emphasizing a lack of pedagogy-wide and long enough research works. Secondly, scholars reviewed relevant research focusing on the use of iPads in higher education, with a focus on student and teacher perspectives [17]. In line with [18], they found that students' learning outcomes were not improved when using tablets. Some benefits for teachers were pinpointed in respect to information dissemination, academic administration and professional development support [17]. A key finding in respect to technology in the form of tablet applications suggests that no up-to-date research that evaluated the use of apps within the subject of mathematics was con- 
ducted. Thirdly, another review [1] evaluated the use of tablets - not just iPads amongst primary and secondary students concerning learning outcomes. The results indicate that the knowledge base was fragmented and lacked rigorous studies sufficient enough to draw any firm conclusions. When discussing technological affordances, it was noted that in consideration of tablet technology, keyboards, larger screens, and specialized software may be needed to support specialized tasks such as mathematical constructions [1]. Finally, one of the latest reviews investigated if, when and how using tablets impacts on learning outcomes [4]. Based on the analysis of 33 studies, including those that were performed in a mathematical education context, they conclude that overall tablets have significant potential for enhancing learning, but "the most important element remains the teacher, and their classroom practice" (p.115).

In summary, the results of the research mentioned above suggest that the tabletmediated learning body of knowledge in education overall lacks the pedagogical sense. Besides, a limitation to complete understanding is that these studies do not specifically address tablets in mathematics but tablets from a broader perspective.

Largely the above-mentioned studies lack the combined focus on tablet-mediated learning in mathematics and do not offer thorough insight into the pedagogical practices, the specific affordances of tablets' use that aid students' learning of mathematics, implementation advantages and specific challenges faced by end-users, teachers and developers.

This study thus aims to fulfil this gap by presenting a systematic review of the literature comprising the tablet-mediated learning body of knowledge with a focus on mathematics.

\subsection{Research questions}

The purpose of this systematic review is to investigate how tablet technology is utilized for mathematics learning and what pedagogical practices tablets support. This is addressed through the following research questions:

- RQ1: In what math-disciplines are tablets used?

- RQ2: What kinds of tablet technology are used?

- RQ3: What kinds of pedagogical practices are enacted?

- RQ4: What are the advantages of tablet-mediated mathematics learning?

- RQ5: What are the challenges of tablet-mediated mathematics learning?

\section{$3 \quad$ Methodology}

To investigate how tablet technology has been utilized for mathematics learning and what pedagogical practices tablets support the existing body of knowledge surrounding tablet-mediated learning in mathematics has been assessed and analysed. Methodological considerations are thus concerned with analysing an aggregate of single research projects that have been conducted in this area and timeframe. 


\subsection{Data collection}

Database searched: Evidence articles were collected from the technology and education-based databases described in Table 1. Databases were selected from an aggregate of those used in previous tablet-mediated and mobile learning systematic reviews (e.g., [1] [17] [18] [22]).

Table 1. Databases searched

\begin{tabular}{|l|l|}
\hline \multicolumn{1}{|c|}{ Database } & \multicolumn{1}{c|}{ Link } \\
\hline ACM Digital Library & http://dl.acm.org/ \\
\hline EBSCO host Research Databases & https://www.ebscohost.com/ \\
\hline ERIC & DB included in EBSCO and ProQuest Searches \\
\hline IEEE Xplore Digital Library & http://ieeexplore.iee.org/Xplore/home.jsp \\
\hline ProQuest & http://www.proquest.com/ \\
\hline ScienceDirect & http://www.sciencedirect.com/ \\
\hline Elsevier Science & DB included in ScienceDirect search \\
\hline
\end{tabular}

Supplemental manual searches - Journals, In order to ensure subject matter coverage of mathematics in education, manual searches were also conducted in for the following journals: Computers \& Education, Journal of Computer Assisted Learning, Computers in Human Behavior, British Journal of Educational Technology, Journal of Educational Technology \& Society, and the International Review of Research in Open and Distance Learning.

Search terms: Three different categorization of search terms and potential variations within those categories were derived from a combination of previous tabletmediated learning systematic reviews by [1] and [17]:

- Tablets: 'tablet' or 'iPad' or 'Android' or 'Windows' AND;

- Education: ‘education' or 'pedagogy' or 'learning' AND;

- Mathematics: 'mathematics' or 'math'.

Selection of papers for inclusion in the review: In respect to timeframe, the scope of this study only included evidence gathered between January 2010 and January 2018.

For assessment of the relevant academic body of knowledge, conference proceedings, articles, and journal publications consisted of the evidence articles collected.

The criteria mentioned above, as well as the following inclusion and exclusion criteria, are adapted from previous systematic reviews [1][17][18]. In addition to the specific criteria stated above, evidence articles were included according to the criteria presented in Table 2: 
Table 2. Inclusion Criteria

\begin{tabular}{|l|l|}
\hline \multicolumn{1}{|c|}{ Inclusion } & \multicolumn{1}{c|}{ Rationale } \\
\hline Focused on any mathematical sub-discipline & $\begin{array}{l}\text { In order to address RQ1, studies that cover such sub- } \\
\text { disciplines (non-exhaustive) as geometry, algebra, } \\
\text { fractions, arithmetic, calculus. }\end{array}$ \\
\hline Reported use of any tablet hardware & $\begin{array}{l}\text { This includes iPads, Android and custom platforms. In } \\
\text { order to address RQ2. }\end{array}$ \\
\hline Reported use of tablet mathematical applications & $\begin{array}{l}\text { In order to address RQ2 for the understanding of what } \\
\text { applications are deployed in mathematics. }\end{array}$ \\
\hline Described pedagogical practices deployed & Concerning RQ3. \\
\hline Written in English Peer-reviewed original articles & Self-explanatory limitation of the researcher. \\
\hline All educational cohorts & $\begin{array}{l}\text { From junior kindergarten to higher learning. Mathemat- } \\
\text { ics is a subject covered at all levels. }\end{array}$ \\
\hline
\end{tabular}

In addition to the specific inclusions stated above, evidence articles were included after exclusion evaluation according to Table 3 .

Table 3. Exclusion Criteria

\begin{tabular}{|l|l|}
\hline \multicolumn{1}{|c|}{ Exclusion } & \multicolumn{1}{c|}{ Rationale } \\
\hline Non-academic sources & $\begin{array}{l}\text { In order to assess the academic body of knowledge, evidence } \\
\text { sources such as news, websites, and other non-peer reviewed } \\
\text { articles were excluded. }\end{array}$ \\
\hline $\begin{array}{l}\text { Mobile learning technology papers that do } \\
\text { not concern tablet technology }\end{array}$ & $\begin{array}{l}\text { Mobile learning technology is a broad topic and tablets is a } \\
\text { subset. It is important to include mobile learning technology } \\
\text { papers where tablets are concerned yet exclude the rest. }\end{array}$ \\
\hline 'Grey Literature' [1] & $\begin{array}{l}\text { Excluded due to non-academic nature or does not fully meet } \\
\text { inclusion criteria. Includes technical writings, white papers, } \\
\text { feasibility studies. }\end{array}$ \\
\hline Duplicates & \begin{tabular}{l} 
Individual searches from databases may yield duplicate returns. \\
\hline
\end{tabular} \\
\hline
\end{tabular}

Coding and categorization of articles: Evidence articles that meet the inclusion criteria were subject to coding by reviewing each article's full text and categorizing the evidence based on the prescribed categories. The categories were derived from the research questions, which were in line with methods used in previous systematic reviews [1] and [18]. Articles in the chosen sample were categorized according to the following non-exhaustive dimensions:

- Math Discipline [RQ1] - The specific math discipline that is the focus of an individual study.

- Utilized Technology [RQ2] - Tablet hardware or software deployed.

- Pedagogical Practices [RQ3] - Commonly identified learning practices applied using technology.

- Advantages [RQ4] - Clear benefits realized from tablet technology.

- Challenges [RQ5] - Commonly documented challenges within evidence articles.

To assess inter-rater reliability concerning the coding of the papers, a sub-sample of 20 of the 39 papers $(50 \%)$ was coded independently by the authors. The inter-rater reliability (r) was .89 , showing good agreement between the coders. 


\section{$4 \quad$ Results}

\subsection{Evidence articles identified by search terms}

Table 4 presents a record of the search query syntax in the form of Boolean strings constructed from the defined search terms. It also includes various notes important to each search that were applied as refinements based on inclusion criteria and the dates that that searches were run. The total number of articles returned from the searches (275 in a six-year period before exclusions) suggests that there may be a limited interest within the area of tablet-mediated learning in mathematics.

\subsection{Evidence articles selected using inclusion criteria}

Table 4 also tallies the number of papers each database yielded as well as how many articles were selected based on the inclusion criteria. The ProQuest search generated the most usable results ( 21 articles), as it also included the ERIC (Education Resources Information Center) databases. In total, 39 relevant articles were found and serve as evidence for this systematic review. A full overview of the reviewed articles is presented in Appendix 1.

\subsection{Categorization results}

\section{Math discipline [RQ1]}

RQ1: In what math-disciplines are tablets used?

Of the 39 articles in the final set:

- Nine articles were related to Arithmetic;

- Six articles were related to Computation;

- Five articles were related to Geometry;

- Nine articles covered multiple disciplines and;

- Algebra, Fractions, Trigonometry, Calculus, Logic and Common Core was also math disciplines of focus.

Arithmetic - Which includes simple addition, subtraction, multiplication, and division - is frequently studied within the tablet-mediated learning mathematics body of knowledge. There is a clear distinction of its use within elementary school levels [26] [27] [28] [30] [31], special needs [32] [33] and even where more advanced equations (and costs) are concerned [34] .

Computation: Evidence articles that reported on the computation sub-discipline are concerned primarily with counting, skip counting, and matching activities [35] [36] [37]. More complex computation activities such as subitizing, quick number judgments [38] [39]; cardinality, number of elements in a number set; relative magnitude, size of a number compared to another; and composition/decomposition, breaking numbers into ones, tens, one hundreds and vice-versa [40] are similarly present. 
Table 4. Databases searched

\begin{tabular}{|c|c|c|c|c|}
\hline Database & Query Syntax & Note & $\begin{array}{l}\text { No. of } \\
\text { Articles }\end{array}$ & \begin{tabular}{|c|}
$\begin{array}{c}\text { No. of Articles } \\
\text { Meeting Inclu- } \\
\text { sion Criteria }\end{array}$ \\
\end{tabular} \\
\hline \begin{tabular}{|l|} 
ACM \\
Digital \\
Library \\
\end{tabular} & $\begin{array}{l}\text { RcordAbstract:(tablet iPad android } \\
\text { windows) AND (education pedagogic } \\
\text { learning ) AND (mathematics math) }\end{array}$ & $\begin{array}{l}\text { Refinements: Published } \\
\text { since } 2010 \text { Published to } \\
2018\end{array}$ & 56 & 6 \\
\hline \begin{tabular}{|l|} 
EBSCO \\
host \\
Research \\
Data- \\
bases
\end{tabular} & $\begin{array}{l}\text { (AB (tablet OR iPad OR android OR } \\
\text { windows)) AND (AB (education OR } \\
\text { pedagogy OR learning)) AND (AB } \\
\text { (mathematics OR math)) }\end{array}$ & $\begin{array}{l}\text { Published Date:20100101- } \\
\text { 20180431Source Types: } \\
\text { Academic Journals, Re- } \\
\text { views, JournalsLanguage: } \\
\text { English }\end{array}$ & 85 & 3 \\
\hline \begin{tabular}{|l|} 
IEEE \\
Xplore \\
Digital \\
Library
\end{tabular} & $\begin{array}{l}\text { (("Abstract":tablet OR "Abstract":iPad } \\
\text { OR "Abstract":android OR "Ab- } \\
\text { stract":windows) AND } \\
\text { (p_Abstract:education OR "Ab- } \\
\text { stract":pedagogy OR "Ab- } \\
\text { stract":learning) AND } \\
\text { (p_Abstract:mathematics OR "Ab- } \\
\text { stract":math)) }\end{array}$ & $\begin{array}{l}\text { Year: 2010-2018 } \\
\text { Content Type: Conference } \\
\text { Publications, Journals }\end{array}$ & 39 & 4 \\
\hline ProQuest & $\begin{array}{l}\text { (AB(tablet) OR AB(iPad) OR } \\
\text { AB(windows) OR AB(android)) } \\
\text { AND (AB(education) OR } \\
\text { AB(learning) OR AB(pedagogy)) } \\
\text { AND (AB(mathematics) OR } \\
\text { AB(math)) }\end{array}$ & $\begin{array}{l}\text { Date: From } 2010 \text { January } 01 \\
\text { to } 2018 \text { April } 31 \\
\text { Source type: Scholarly } \\
\text { Journals } \\
\text { Language: English }\end{array}$ & 67 & 21 \\
\hline $\begin{array}{l}\text { Sci- } \\
\text { enceDi- } \\
\text { rect }\end{array}$ & $\begin{array}{l}\text { pub-date > } 2009 \text { and TITLE-ABSTR- } \\
\text { KEY((("tablet" OR "ipad" OR "an- } \\
\text { droid" OR "windows") AND ("educa- } \\
\text { tion" OR "pedagogy" OR "learning") } \\
\text { AND ("mathematics" OR "math"))) }\end{array}$ & $\begin{array}{l}\text { Date Range: '2010' to } \\
\text { 'Present' }\end{array}$ & 28 & 5 \\
\hline & & Total & 275 & 39 \\
\hline
\end{tabular}

Geometry: A more complex math sub-discipline than arithmetic and computation, geometry applications take advantage of tablet technology when interacting with environments through camera and compass functions. This is demonstrated in learning situations by capturing angles and distance measurements of real-world images [41] [42]. More advanced geometric activities include i) spatial geometry, consisting of points, lines, polygons [43], ii) translation, reflection, and rotation [44]; and iii) 3D Geometry where users can manipulate shapes in the third dimension using hand gestures and touchscreens [45]

Multi-discipline articles: There were multiple articles where a specific math subdiscipline was either not mentioned. These covered the broader topic of mathematics yet discussed either important pedagogical/technology approaches [10] [15] [46] [47] [48] or multiple math sub-disciplines were researched. In cases where multiple subdisciplines were discussed, geometry mixed with fractions [49], geometry mixed with computation activities [50]; and mathematical problem solving [51] [52] was identified.

Other math disciplines: More complex math sub-disciplines require more specialized applications that potentially reach smaller educational audiences than foundation level sub-disciplines such as arithmetic and computation in elementary settings. The 
least complex fractions [53] [54] and algebra [55] [56] accounted for two evidence articles respectively. At the more complex end of the math spectrum, calculus [57] [58] and trigonometry [59] [60] also accounted for two findings each. A sole article researched mathematical logic [61].

\subsection{Utilized technology [RQ2]}

RQ2: How is the tablet technology used? What kinds of hardware/applications are utilized?

Of the 39 evidence articles in the final set:

- 26 articles were based on the iPad tablet;

- Six articles were based on the Android platform;

- The remaining articles' hardware was either not named or purely custom solutions;

- Frequently studied applications included Motion Math and

- Many custom apps were studied.

Tablet hardware technology: Collected evidence supports the notion that Apple may have the educational market covered as $67 \%$ of articles deployed iOS based tablets such as the iPad (e.g., [15] [31] [45] [46] [49] [50] [55] [61]).The Android platform has less evidence in support. Many companies develop tablets that run Android, yet the Samsung Galaxy Tab is the only device specifically researched [27] [43] [59]. Other articles present an Android solution but do not specifically state which manufacturer has supplied the tablet [34] [36] [56].

Seven articles do not specifically state what the underlying hardware technology solution is, thus focusing purely on the application itself (e.g., [28] [29] [44] [51] [52]). These kinds of studies are important because they can help explain whether it is the hardware or the software side of technology that impacts other researched factors (i.e., pedagogical approaches).

\subsection{Pedagogical practices [RQ3]}

RQ3: What kind of pedagogical practices are enacted?

Of the 39 evidence articles in the final set:

- 16 articles were based on Game-Based Learning;

- Five articles were based on some form of Environment Interaction;

- Four articles were customized for Special Needs Learning;

- Other frequent pedagogical approaches included: Feedback, Scaffolding, Drill and Practice, and Reciprocal Peer Tutoring.

Game-based learning: It is no surprise that there is a large volume of evidence in support of game-based learning as a pedagogical practice. The logic is somewhat simple too: games are fun. Therefore math-based games can be fun too. They engage the student in what can be seen by some as mundane math topics presented in a fun way [15] and one case potential for distraction [48]. So, researched was game-based 
learning as a pedagogical approach that multiple articles focused purely on it [27] [39] [53] [54] [61] [62]. Other evidence combines game-based learning with other pedagogical approaches, such as i) environment interaction, where the tablet technology interfaces with the real world [38] [57]; ii) feedback, where results and comments or positive reinforcement are immediately communicated to the user/student [28] [40]; and iii) immersion through flow experience, i.e., being in the zone [26] or through repetition of math levels [56].

Environment interaction: Utilizing tablet hardware features such as cameras, gyros, GPS and compasses, they can easily interact with the outside environment. This is especially true where geometry apps are concerned. Angles and shapes can be extrapolated from pictures, location data from GPS and other such measures can be inputs from the student's environment. As a pedagogical approach, using the real-world environment makes understanding practical applications easier for the learner [37] [42] and can even bring learning into the third dimension which is more difficult on paper [45].

Special needs learning: Since tablet technology is extremely customizable, special needs pedagogical approaches are customized. Physical disabilities can be accounted for through a specialized touch-input system that removes previous limitations of pencil and paper and enables learning to draft complex trigonometric equations [59]. Combined with environment interaction, game-based learning, and drill \& practice pedagogies, down-syndrome [36] or autism [32] students can also be taught mathematics. Scaffolding, or level of support given during learning, is also combined with special needs learning [30] to offer a customized pedagogical approach.

Other pedagogical approaches: Feedback and scaffolding are also commonly utilized in pedagogical approaches. They have been used within games [38], as standalone approaches [46] [47] or in combination with a virtual tutor [34] [50].

Drill and practice, a traditional pedagogical approach where apps provide welldesigned learning based on repeated drill-and practice [33] are also frequent approaches. Such approach was found to be combined with tech and test - another traditional approach - to validate the repetition for average [43], as well as special needs students [36].

Another pedagogical approach to be mentioned is that of reciprocal peer tutoring. This is identified to be enabled by network and real-time communication features where learners can solve math problems within an app but also use the same app to demonstrate and teach other learners through video [44] and visual communication [41] [52] [60].

\subsection{Advantages [RQ4]}

RQ4: What are the advantages of tablet mediated mathematics learning?

Collaborative learning: As one of the primary affordances of tablet technology is its collaborative features (e.g., network and email), there is strong evidence in support of the advantages with respect to collaborative learning. Scribing, peer assessment, learning by teaching or "show and tell" are collaborative advantages whereby students can draw, build, and/or solve mathematical equations, diagrams or representations that 
subsequently can be visually shown to other students and teachers. This enhances mathematical communication of all involved as students are motivated to clarify and reflect their ideas (e.g., [10] [31] [41].

Mobility: Since tablets are lightweight, wireless, and have long-lasting batteries, there is evidence to support that mobility of the devices is an advantage that is exploited in mathematics learning [44]. The mobility of the devices can lead to arguments against using PC or laptop technology. Laptops are too unwieldy for two students to compare work. Putting two tablets side-by-side is more practical than laptops [57]. Such kind of mobility also leads to the creation of engaging learning environments beyond the traditional boundaries of a classroom: the mobility of tablets result in altering the physical structure of the classroom as well as promoting a classroom environment is more conducive to learning mathematics [61].

Level of customization: The sheer volume of presented in the chosen sample custom math applications is a testament to the seemingly infinite number of ways that tablet technology can be customized. The most researched type of customization was when usable interfaces are designed to the specific needs of the end users - creating an easy-to-use interface. Whether it regards special needs [36] [59] or a more standard interface [37] [49] [54], students need to be comfortable with how they interact with their devices.

Customization of apps with respect to digital tutors or other kinds of built-infeedback was shown to lead to a lowered requirement for direct teacher support [32]. Additionally, apps were shown to serve as teaching tools or purely learning tools [27], as well as tools used for measurement of teaching effectiveness [40].

Mathematics engagement: Games, visuals, and rewards lend themselves to students being more engaged in mathematics. Overall, the most important factor in mathematics engagement is that math apps are fun [28]. Learners and teachers are most engaged when they are having fun. As outlined by [56], the video game was able to provide entertainment and at the same time was contextually relevant. Even compared to traditional methods such as "chalk \& talk," levels of engagement and focus are much higher when tablet technology is used [44]. It is even demonstrated that highly engaged or even variably engaged students to achieve learning gains when utilizing tablets [62].

\subsection{Challenges [RQ5]}

RQ5: What are the challenges of tablet mediated mathematics learning?

Design/Content: One of the major challenges when it comes to deploying tablet technology in mathematics is getting the design of the solution correct which includes having the right content for the learner/teacher end users. Potential design issues include but are not limited to blurred images from cameras [44], light sensitivity settings [45], inadequately accounting for personal disabilities [59], poor user interfaces [29] [59], and at the most extreme, "inadequacies in representing the accuracy and richness of the mathematics content" [47]. Failure in design and content can lead to costly re-design or abandonment of the solution altogether by the students or teachers 
as extreme examples. Minor design failures can lead to an increased need for technical support or maintenance teams to be onsite [31] [32] [40] [58].

Solutions to this challenge have been suggested in various application design approaches such as user-centered design [55] and ethnographic design [34].

Cognitive load: The cognitive load placed on students is also a definite challenge as new technology, interfaces, and new math applications first need to be learned themselves before students and teachers can capture the full potential of the learning experience [36] - the brain can only process so much. It has been demonstrated that "extraneous cognitive load can interfere with learning" [48] and lead to distractions within the learning environment. Cognitive load can lead to an increased need for technical training (cost) in addition to learning the math subject being taught [42].

This potential for 'information overload' is a challenge for designers as solutions tend to be based on hardware where potential users already have a technical ability due to ownership at home or elsewhere in an attempt to address this challenge [37].

Another possible solution presented is the use of pre-task instruction in order to alleviate potential high cognitive load that can lead to "digital interface performance deficits" [43].

Hardware vs. Software: A challenge to researchers is represented in the difficulty of "disentangling the exact features of the software and hardware" that defines a given study or intervention as successful [50]. This is a product of the fact that software cannot operate without a hardware platform. An attempt to overcome this challenge was an intervention with three groups: one with a tablet and math app; one with a tablet without the app; and a control group representing a traditional classroom without technology [46]. Even then, deciphering whether it is the hardware or the software that benefitted learners or teachers or resulted in some form of technological limitation remained a challenge [58].

Comparison against traditional methods: Another important challenge that needs to be addressed is the comparison between traditional teaching methods or pedagogical approaches versus those that are enhanced by tablet technology. Comparing enhanced learning environments to the traditional will set a benchmark to measure the effects of tablets within mathematics learning [56]. Unfortunately, there is limited evidence available to support that research is conducting these kinds of comparisons in order to alleviate this challenge [35] [53].

Novelty: The most interesting challenge and a question on researchers' minds are that of novelty. What happens when games are no longer fun or technology is no longer exciting? It "is commonly found in learning processes, the gains attributed to the novelty of a new approach may eventually become attenuated over time" [62]. More evidence is required to support the notion of novelty, and it impacts on tablet mediated learning in mathematics [10].

\section{Discussion}

This systematic review aimed to investigate how tablet technology is utilized for mathematics learning. In particular, it focused at the understanding of in what math- 
disciplines tablets were used; what kind of tablet technology was employed; what pedagogical practices were enacted, as well as at the understanding of advantages and challenges of tablet-mediated mathematics learning.

\subsection{Foundational mathematics is the dominant math discipline}

The results show that there is a clear focus on foundational level mathematics in elementary school settings. Arithmetic (addition, subtraction, multiplication, and division) and computation (counting, number sorting/ordering, and subtilizing) are simple mathematical teaching concepts and lay the groundwork for more complex topics such as geometry, algebra, trigonometry, and calculus. Thus foundation subjects that tend to reach a wider audience of learners will be subject to application development and deployment on tablet hardware in educational settings in higher volume and frequency than more complex applications dealing with, for example, 3D geometry.

\subsection{Pedagogical approaches}

The most used pedagogical approach, either standalone or combined with others is game-based learning. Tablet technology opens the door for mathematical games to be designed that are touchscreen based, networked, visually and audibly stimulating and most of all fun. The ability to make complex and boring math subjects into fun and engaging experiences are strongly desired by teachers and learners. Except for gamebased learning, the reviewed studies either specifically targeted pedagogical approaches or inferred the existence of approaches used. Such table features as cameras, GPS, WiFi, and compasses enable unique opportunities for students and teachers to interact with their environments. Pictures of houses can turn into geometry lessons, and wireless network connections can ensure that students can collaborate and teachers can provide real-time feedback or scaffolding to assist teaching efforts. Special needs pedagogical approaches also not only include games, feedback, environmental interaction, and scaffolding but can be customized depending on physical or mental disability. Students who have lost the use of their hands for example can have custom interfaces developed which limit the impact of the physical disability when interfacing with tablets. These approaches, as well as traditional drill and practice or teach and test, can be programmed and deployed on top of tablet technology. Tablets allow teachers and students to customize their learning by selecting pedagogical approaches relevant to an individual student and/or a specific mathematical subject.

\subsection{Advantages of deploying tablets}

The affordances of tablets are widely researched and generally accepted in mobile learning circles. Coincidently, the evidence gathered in this review identifies some of the main advantages of tablets deployed in mathematics learning and directly links to tablet affordances [4]. For example, the collaborative affordances of tablet technology - related to, e.g., Wifi, graphical output, and document sharing - translates into math classrooms in which increased levels of collaborative learning is manifested where 
students can act as peer-tutors and use tablets to solve math problems but also teach and gain peer feedback from other students. Students and teachers also take advantage of the portability and mobility of the technology when setting up unique learning experiences outside of the traditional classroom settings. These advantages, coupled with gaming pedagogical approaches lead to increased levels of mathematical engagement of students when compared to traditional classrooms and tools [63]. Perhaps the prevalent discovered benefit is the level of customization that tablet technology can bring to the student learning experience. Not only can applications be customized to include various pedagogical approaches, but apps can also be tailored toward the specific mathematical sub-disciplines being taught. Lastly, hardware can be customized to interact with external environments or even provide usable interfaces to accommodate special needs students.

\subsection{Challenges faced by researchers, teachers, and students}

While this review has mainly focused on the positive aspects of tablet technology, there is evidence to suggest that a few key challenges are also present. Design and content challenges plague not only developers but also teachers: how to best design the app for its intended audience and ensure that content is not only relevant but easily understood and navigated by learners is a constant challenge. Development of math apps can take multiple iterations and testing using classroom interventions of variable design. Teachers also face the challenge of how to design effective learning experiences that not only incorporate tablet technology but also apt mathematical pedagogical approaches.

Design and content challenges also need to consider the cognitive load challenge, i.e., interfacing with tablet technology should not put an extraneous cognitive load onto teachers and/or students. Time spent learning how to use an app or tablet interface can negatively impact mathematic teaching, as more time can be spent with technology learning than the subject at hand. The results also show that where there is a demand for high cognitive load, there is also a requirement for increased levels of technical support/maintenance from IT experts for teachers and students - which suggests a financial and time cost.

\subsection{The novelty factor}

When analysing other minor challenges one less frequently spoken of, yet very interesting and potentially high impact disadvantage came to the forefront - that of novelty. It is yet to be determined whether the novelty of technology fades over time and student/teacher engagement becomes less fun or less exciting as a result. The majority of evidence in this review seems to support the premise that tablet technology in iOS-based teaching is primarily deployed, and perhaps most effective in elementary school levels. That being said, it opens the door to further investigation to determine when the novelty of tablets essentially runs its course as students' progress in grades (potentially leading to disengagement and boredom) or improve other learning outcomes. 


\subsection{Limitations}

This systematic review has several limitations. The first of which is a common limitation facing all systematic reviews - building the snapshot in time of the body of knowledge around tablet mediated learning in mathematics. Necessary conditions of this limitation include

- The exact search parameters represented by the Boolean strings

- The databases searched and choice of inclusion criteria; and the exact time the searches were performed, as well as the time period sample

Since in 2018, we are in the "late majority" maturity level of tablet technology, not only was this potentially a good time for a snapshot but this was also dependent on the almost commonly accepted notion that 2010 was the beginning of the latest generation of tablet technology.

Lastly, the databases themselves and the searches within them were limited to English only results. It follows then that all evidence and findings are limited to one language and not a representative extrapolation of the entire global body of knowledge for tablet mediated learning in mathematics.

\section{Conclusion}

This systematic review representing the latest generation of tablet technology within the tablet-mediated learning in mathematics body of knowledge sought to derive evidence that supported questions into what math sub-disciplines, what technology and what pedagogical approaches were deployed in educational settings. This included an analysis of the advantages and disadvantages present in those elements.

The most notable finding was that with a low volume of evidence articles in support of tablet-mediated learning in mathematics, the overall body of knowledge requires much more academic development. Researchers going forward should focus on specific mathematical sub-disciplines such as calculus, algebra, trigonometry and mathematical logic with a comparative look into which pedagogical approaches are effective in more complex math vs. foundational math subjects. Comprehensive endto-end studies that look at tablet technology and pedagogy are needed.

A potential disadvantage discovered also requires more research into the impact of novelty over time. It is plausible to suggest to novelty is not infinite and game base learning or tablet technology may become less interesting in older learning cohorts or even in corporate learning situations and be viewed more as a tool rather than a novel device.

What this study has shown is that despite almost eight years into this generation of tablet technology, the body of knowledge in respect to tablet-mediated learning in mathematics is still limited. Most research to date has focused on broader topics of mobile learning. In closing, it is hoped that this review will serve as a guide and a tool for tablet technology developers, teachers/students and researchers in the field of the tablet- mediated learning in mathematics. 


\section{$7 \quad$ References}

[1] Hassler, B., Major, L., \& Hennessy, S. (2016, April). Tablet use in schools: a critical review of the evidence for learning outcomes. Journal of Computer Assisted Learning, 32(2), 139-156. https://doi.org/10.1111/jcal.12123

[2] Volk, M., Cotič, M., Zajc, M., \& Starcic, A. I. (2017). Tablet-based cross-curricular maths vs. traditional maths classroom practice for higher-order learning outcomes. Computers \& Education, 114, 1-23. https://doi.org/10.1016/j.compedu.2017.06.004

[3] Woods, V., \& van der Meulen, R. (2016). Worldwide Device Shipments to Grow 1.9 Percent in 2016, While End-User Spending to Decline for the First Time. Retrieved January 20, 2017, from gartner.com: http://www.gartner.com/newsroom/id/3187134

[4] Major, L., Haßler, B., \& Hennessy, S. (2017). Tablet use in schools: impact, affordances and considerations. In Handbook on digital learning for K-12 schools, 115-128. Springer, Cham. https://doi.org/10.1007/978-3-319-33808-8 8

[5] Department for Education and Crown Commercial Service. (2016, April 28). Register to buy tablet devices for your school. Retrieved January 20, 2017, from gov.uk: https://www.gov.uk/government/news/register-to-buy-tablet-devices-for-your-school

[6] Tamim, R., Borokhovski, E., Pickup, D., \& Bernard, R. (2015). Large-Scale, GovernmentSupported Educational Tablet Initiatives. Retrieved from Commonwealth of Learning: http://oasis.col.org/bitstream/handle/11599/809/COL\%20Tablet\%20Initiatives.pdf?sequen ce $=1 \&$ isAllowed $=y$

[7] Trucano, M. (2013, July 31). Big educational laptop and tablet projects -- Ten countries to learn from. Retrieved February 2, 2018, from The World Bank: http://blogs.world bank.org/edutech/big-educational-laptop-and-tablet-projects-ten-countries

[8] Blackwell, C. K., Lauricella, A. E., \& Wartella, E. (2016). The influence of TPACK contextual factors on early childhood educators' tablet computer use. Computers \& Education, 98(2). https://doi.org/10.1016/j.compedu.2016.02.010

[9] Price, S., Jewitt, C., \& Crescenzi, L. (2015). The role of iPads in pre-school children's mark making development. Computers \& Education, 87, 131-141. https://doi.org/10. 1016/j.compedu.2015.04.003

[10] Ingram, N., Williamson-Leadley, S., \& Pratt, K. (2016). Showing and Telling: Using Tablet Technology to Engage Students in Mathematics. Mathematics Education Research Journal, 28(1), 123-147. https://doi.org/10.1007/s13394-015-0162-y

[11] Rossing, J., Miller, W., Cecil, A., \& Stamper, S. (2012). iLearning: The future of higher education? Student perceptions on learning with mobile tablets. Journal of the Scholarship of Teaching and Learning, 12(2), 1-26.

[12] Nouri J. \& Cerratto Pargman, T. (2016). When Teaching Practices Meet Tablets' Affordances. Insights on the Materiality of Learning. In: K. Verbert, M. Sharples \& T. Klobučar (Eds.) Adaptive and Adaptable Learning. EC-TEL 2016. Lecture Notes in Computer Science, vol. 9891, 179-192. Cham: Springer. https://doi.org/10.1007/978-3-31945153-4 14

[13] Hu, H., \& Garimella, U. (2014). iPads for STEM teachers: A case study on perceived usefulness, perceived proficiency, intention to adopt, and integration in K-12 instruction. Journal of Educational Technology Development and Exchange (JETDE), 7(1), 4. https://doi.org/10.18785/jetde.0701.04

[14] Zydney, J. M., \& Warner, Z. (2016). Mobile apps for science learning: Review of research. Computers \& Education, 94, 1-17. https://doi.org/10.1016/j.compedu.2015.11. $\underline{001}$ 
[15] Carr, J. (2012). Does Math Achievement "h'APP'en" when iPads and Game-Based Learning Are Incorporated into Fifth-Grade Mathematics Instruction? Journal of Information Technology Education, 11(1), 269-286. https://doi.org/10.28945/1725

[16] Cheung, A. C., \& Slavin, R. E. (2013). The effectiveness of educational technology applications for enhancing mathematics achievement in K-12 classrooms: A meta-analysis. Educational Research Review, 9, 88-113. https://doi.org/10.1016/j.edurev.2013.01.001

[17] Nguyen, L., Barton, S. M., \& Nguyen, T. (2015, January). iPads in higher education Hype and Hope. British Journal of Educational Technology, 46(1), 190-203. https://doi. org/10.1111/bjet.12137

[18] Dhir, A., Gahwaji, N. M., \& Nyman, G. (2013). The Role of the iPad in the Hands of the Learner. Journal of Universal Computer Science, 19(5), 706-727.

[19] Slavin, R. E., \& Lake, C. (2008). Effective Programs in Elementary Mathematics: A BestEvidence Synthesis. Review of Educational Research, 78(3), 427-515. https://doi.org/10.31 $\underline{02 / 0034654308317473}$

[20] Rakes, C., Valentine, J., McGatha, M., \& Ronau, R. N. (2010). Methods of Instructional Improvement in Algebra: A Systematic Review and Meta-Analysis. Review of Educational Research, 80(3), 372-400. https://doi.org/10.3102/0034654310374880

[21] Taylor, J., Sharples, M., O’Malley, C., Vavoula, G., \& Waycott, J. (2006). Towards a task model for mobile learning: a dialectical approach. International Journal of Learning Technology, 2(2), 138-158. https://doi.org/10.1504/ijlt.2006.010616

[22] Frohberg, D., Göth, C., \& Schwabe, G. (2009). Mobile Learning Projects - a critical analysis of the state of the art. Journal of Computer Assisted Learning, 25(4), 307-331. https://doi.org/10.1111/j.1365-2729.2009.00315.x

[23] Bano, M., Zowghi, D., Kearney, M., Schuck, S., \& Aubusson, P. (2018). Mobile learning for science and mathematics school education: A systematic review of empirical evidence. Computers \& Education, 121, 30-58. https://doi.org/10.1016/j.compedu.2018.02. $\underline{006}$

[24] Crompton, H., \& Burke, D. (2015). School culture for the mobile digital age. Media Education, 6(2).

[25] Drigas, A., \& Pappas, M. (2015). A review of mobile learning applications for mathematics. International Journal of Interactive Mobile Technologies (iJIM), 9(3), 18-23. https://doi.org/10.3991/ijim.v9i3.4420

[26] Hung, C.-Y., Chih-Yuan Sun, J., \& Yu, P.-T. (2015). The benefits of a challenge: Student motivation and flow experience in tablet-PC-game-based learning. Interactive Learning Environments, 23(2), 172-190. https://doi.org/10.1080/10494820.2014.997248

[27] Masood, Z., \& Hoda, R. (2014). Math Tutor: An Interactive Android-based Numeracy Application for Primary Education. Proceedings of the Fifteenth Australasian User Interface Conference. 150. Auckland: SEPTA Research, Electrical and Computer Engineering, The University of Auckland.

[28] van der Ven, F., Segers, E., Takashima, A., \& Verhoeven, L. (2017). Effects of a tablet game intervention on simple addition and subtraction fluency in first graders. Computers in Human Behavior, 72, 200-207. https://doi.org/10.1016/j.chb.2017.02.031

[29] Halloluwa, T., Vyas, D., Usoof, H., Hewagamage, K., \& Sahama, T. (2016). Gamifying Mathematics for Primary Students in Rural Sri Lanka. Proceedings of the 9th Nordic Conference on Human-Computer Interaction: Game-Changing Design. Association for Computing Machinery. https://doi.org/10.1145/2971485.2971522

[30] Zhang, M., \& Asam, R. (2015). Using Math Apps for Improving Student Learning: An Exploratory Study in an Inclusive Fourth Grade Classroom. TechTrends: Linking Research 
and Practice to Improve Learning, 59(2), 32-39. https://doi.org/10.1007/s11528-015-0837$\mathrm{y}$

[31] Soto, M. (2015). Elementary Students' Mathematical Explanations and Attention to Audience with Screencasts. Journal of Research on Technology in Education, 47(4), 242258. https://doi.org/10.1080/15391523.2015.1078190

[32] O'Malley, P., Lewis, M., Donehower, C., \& Stone, D. (2014). Effectiveness of Using iPads to Increase Academic Task Completion by Students with Autism. Universal Journal of Educational Research, 2(1), 90-97.

[33] Bryant, B. Ok, M., Kang, E., Kim, M., Land, R., Bryant, D., \& Pfannestiel, K. (2015). Performance of fourth-grade students with learning disabilities on multiplication facts comparing teacher-mediated and technology-mediated interventions: A preliminary investigation. Jounal of Behavioral Education, 24(2), 255-272. https://doi.org/10.1007/s10 $\underline{864-015-9218-\mathrm{Z}}$

[34] Kumar, V., Sinha, A., Dhareshwar, A., \& Joshi, L. (2015). Mathematics Tutoring Apps for Low-Cost Devices: An Ethnographic Study of Requirements. Proceeding of the 3rd International Symposium on Women in Computing and Informatics (pp. 729-733). ACM. https://doi.org/10.1145/2791405.2791563

[35] Mattoon, C., Bates, A., Shifflet, R., Latham, N., \& Ennis, S. (2015). Examining Computational Skills in Prekindergarteners: The Effects of Traditional and Digital Manipulatives in a Prekindergarten Classroom. Early Childhood Research \& Practice, $17(1), 9$.

[36] Ahmad, W., Muddin, H., \& Shafie, A. (2014). Number skills mobile application for down syndrome children. 2014 International Conference on Computer and Information Sciences, ICCOINS 2014 - A Conference of World Engineering, Science and Technology Congress, ESTCON 2014 - Proceedings, 2014 International Conference on Computer and Information Sciences. Institute of Electrical and Electronics Engineers Inc. https://doi.org/ $\underline{10.1109 / \text { iccoins.2014.6868844 }}$

[37] Tucker, S., Moyer-Packenham, P., Westenskow, A., \& Jordan, K.(2016). The complexity of the affordance-ability relationship when second-grade children interact with mathematics virtual manipulative apps. Technology, Knowledge and Learning, 21(3), 341360. https://doi.org/10.1007/s10758-016-9276-x

[38] Barendregt, W., Lindström, B., Rietz-Leppänen, E., Holgersson, I., \& Ottosson, T. (2012, June). Development and evaluation of Fingu: A mathematics iPad game using multi-touch interaction. In Proceedings of the 11th international conference on interaction design and children (pp. 204-207). ACM. https://doi.org/10.1145/2307096.2307126

[39] Schacter, J., \& Jo, B. (2016). Improving low-income preschoolers mathematics achievement with Math Shelf, a preschool tablet computer curriculum. Computers in Human Behavior, 55, 223-229. https://doi.org/10.1016/j.chb.2015.09.013

[40] Blair, K., Cutumisu, M., Hallinen, N., Schwartz, D., \& Pfaffman, J. (2015). Testing the Effectiveness of iPad Math Game: Lessons Learned from Running a Multi-Classroom Study. Conference on Human Factors in Computing Systems (pp. 727-734). Association for Computing Machinery. https://doi.org/10.1145/2702613.2702974

[41] Harless, P. (2011). SCRIBING: A Technology-Based Instructional Strategy. Mathematics Teacher, 104(6), 420-425.

[42] Crompton, H. (2015). Using Context-Aware Ubiquitous Learning to Support Students' Understanding of Geometry. Journal of Interactive Media in Education, 2015(1), http://doi.org/10.5334/jime.aq. 
[43] Goodman, S., Seymour, T., \& Anderson, B. (2016). Achieving the performance benefits of hands-on experience when using digital devices: A representational approach. Computers in Human Behavior, 59, 58-66. https://doi.org/10.1016/j.chb.2016.01.006

[44] Ramkalawon, L., \& Bholoa, A. (2016). Using tablet PC in the teaching and learning of secondary mathematics: A case of a girl's class in Mauritius. Proceedings of 2016 SAI Computing Conference (pp. 850-857). Institute of Electrical and Electronics Engineers Inc. https://doi.org/10.1109/sai.2016.7556078

[45] Bertolo, D., Nigay, L., Pelurson, S., \& Vivian, R. (2015). Exploratory Experimentation of Three Techniques for Rotating a 3D Scene by Primary School Students. IHM 2015 - Actes de la 27eme Conference Francophone sur l'Interaction Homme-Machine. Association for Computing Machinery, Inc. https://doi.org/10.1145/2820619.2825024

[46] Pitchford, N. (2015). Development of early mathematical skills with a tablet intervention: A randomized control trial in Malawi. Frontiers in Psychology. https://doi.org/10.3389/ fpsyg.2015.00485

[47] Cayton-Hodges, G. A., Feng, G., \& Pan, X. (2015). Tablet-Based Math Assessment: What Can We Learn from Math Apps? Journal of Educational Technology \& Society, 18(2), 320.

[48] McEwen, R. N., \& Dubé, A. K. (2015). Engaging or distracting: Children's tablet computer use in education. Educational Technology \& Society, 18(4), 9-23.

[49] Dubé, A., \& McEwen, R. (2015). Do gestures matter? The implications of using touchscreen devices in mathematics instruction. Learning and Instruction, 40, 89-98. https://doi.org/10.1016/j.learninstruc.2015.09.002

[50] Outhwaite, L., Gulliford, A., \& Pitchford, N. (2017). Closing the gap: Efficacy of a tablet intervention to support the development of early mathematical skills in UK primary school children. Computers \& Education, 43-58. https://doi.org/10.1016/j.compedu.2017.01.011

[51] Muis, K. R., Psaradellis, C., Chevrier, M., Di Leo, I., \& Lajoie, S. P. (2016). Learning by preparing to teach: Fostering self-regulatory processes and achievement during complex mathematics problem solving. Journal of Educational Psychology, 108(4), 474-492. https://doi.org/10.1037/edu0000071

[52] Yang, E., Chang, B., Cheng, H., \& Chan, T.-W. (2016). Improving pupils' mathematical communication abilities through computer-supported reciprocal peer tutoring. Journal of Educational Technology \& Society, 19(3), 157-169.

[53] Riconscente, M. M. (2013). Results From a Controlled Study of the iPad Fractions Game Motion Math. Games and Culture, 8(4), 186-214. https://doi.org/10.1177/1555412013496 894

[54] Ninaus, M., Kiili, K., McMullen, J., \& Moeller, K. (2017). Assessing fraction knowledge by a digital game. Computers in Human Behavior, 70, 197-206. https://doi.org/10.1016/j.c hb.2017.01.004

[55] Isabwe, G., \& Reichert, F. (2012). Developing a formative assessment system for mathematics using mobile technology: A student centred approach. 2012 International Conference on Education and e-Learning Innovations (pp. 1-6). ICEELI 2012. https://doi. org/10.1109/iceeli.2012.6360619

[56] Siew, N., Geofrey, J., \& Lee, B. (2016). Students' Algebraic Thinking and Attitudes towards Algebra: The Effects of Game-Based Learning using Dragonbox $12+$ App. Electronic Journal of Mathematics \& Technology, 10(1), 1-17.

[57] , B., Lucas, T., \& Galstyan, A. (2013). The role of iPads in constructing collaborative learning spaces. Technology, Knowledge and Learning, 18(3), 165-178. https://doi.org/1 $\underline{0.1007 / \mathrm{s} 10758-013-9207-\mathrm{Z}}$ 
[58] Isabwe, G. (2012). Investigating the usability of iPad mobile tablet in formative assessment of a mathematics course. International Conference on Information Society (pp. 39-44). iSociety 2012.

[59] Choi, K., \& Chan, T. (2015). Facilitating mathematics learning for students with upper extremity disabilities using touch-input system. Disability And Rehabilitation. Assistive Technology, 10(2), 170-180. https://doi.org/10.3109/17483107.2013.873490

[60] Audi, D., \& Gouia-Zarrad, R. (2013). A New Dimension to Teaching Mathematics Using iPads. 13th International Educational Technology Conferenc (pp. 51-54). Elsevier Ltd. https://doi.org/10.1016/j.sbspro.2013.10.306

[61] Kyriakides, A., Meletiou-Mavrotheris, M., \& Prodromou, T. (2016). Mobile Technologies in the Service of Students' Learning of Mathematics: The Example of Game Application A.L.E.X. in the Context of a Primary School in Cyprus. Mathematics Education Research Journal, 28(1), 53-78. https://doi.org/10.1007/s13394-015-0163-x

[62] Deater-Deckard, K., El Mallah, S., Chang, M., Evans, M. A., \& Norton, A. (2014). Student behavioral engagement during mathematics educational video game instruction with 11-14 year olds. International Journal of Child-Computer Interaction, 2(3), 101-108. https://doi.org/10.1016/j.ijcci.2014.08.001

[63] Papadakis, S., Kalogiannakis, M., \& Zaranis, N. (2016). Comparing tablets and PCs in teaching mathematics: An attempt to improve mathematics competence in early childhood education. Preschool and Primary Education, $4(2), 241-253$.

\section{Authors}

Alexander Svela has done M.Sc in Computer Science, Department of Computer and System Sciences, Stockholm University.

Jalal Nouri is an Associate professor and researcher in TEL, Department of Computer and System Sciences, Stockholm University.

Olga Viberg is an Associate professor and researcher in TEL, Royal Institute of Technology

Lechen Zhang is a PhD candidate in TEL, Department of Computer and System Sciences, Stockholm University

Article submitted 2019-05-06. Resubmitted 2019-06-17. Final acceptance 2019-06-18. Final version published as submitted by the authors. 